\title{
Ethical Guidelines for Conducting Experiments and Writing Scientific Reports in Psychology
}

\author{
María Antonia Padilla Vargas ${ }^{1}$ \\ ${ }^{1}$ Centro de Estudios e Investigaciones en Comportamiento, University of Guadalajara, Jalisco, México \\ Correspondence: María Antonia Padilla Vargas, Centro de Estudios e Investigaciones en Comportamiento, \\ Universidad de Guadalajara, Francisco de Quevedo 180, Col. Arcos Vallarta, Guadalajara, Jalisco, México. Tel: \\ 52-0133-3818-0730. E-mail: tony.padilla2008@gmail.com
}

Received: May 21, 2016

Accepted: June 1, 2016

Online Published: June 16, 2016

doi:10.5539/ijps.v8n3p1

URL: http://dx.doi.org/10.5539/ijps.v8n3p1

\begin{abstract}
Recently, many cases of scientific malpractice have been reported, and their severity has resulted in the dismissal of those involved, the rescission of academic degrees, expulsion from academic organizations, and even prison sentences. Because it is essential to provide ethical training to people involved in scientific research, the objective of this paper is to describe the ethical guidelines that everyone who conducts experiments in psychology must observe, especially when human participants are involved. These guidelines are also applicable to authors of scientific papers. Our goal is to contribute to ensuring the ethical performance of scientific work. Also, in an effort to eradicate scientific malpractice, we propose implementing a three-pronged strategy: first, working with academic institutions (universities, research centers, etc.) to provide ongoing training in the ethical aspects of the discipline in question to all personnel involved in scientific work (researchers, technicians, professors, students); second, designing strategies for constant, close supervision to guarantee that all scientific activities adhere to the applicable ethical standards; and, third, defining mechanisms to establish and then apply sanctions in the event of scientific malpractice, including the creation of organs entrusted with organizing and implementing these activities.
\end{abstract}

Keywords: scientific malpractice, ethics, scientific research, report writing, psychology

\section{Introduction}

In recent months, several cases of plagiarism have come to light in Mexico. The serious nature of these incidents has resulted in the expulsion of plagiarists from Mexico's National System of Researchers (SNI) (a federal government agency that rewards quality scientific work with a monthly economic stimulus), dismissal from their positions, and public exposure on social networks (Martínez, 2015). One particularly notorious case involved the well-known Dutch social psychologist, Diederik Stapel, who in addition to being fired was about to have his Doctoral degree rescinded, though he opted to renounce it before that measure was taken. This transpired after the discovery that he had falsified data in at least 30 of his published articles (De Martos, 2011).

But cases of plagiarism or falsification (i.e., malpractice in performing experiments) can bring an even graver consequence: imprisonment. To cite one example, in July, 2015, Dong Pyou Han, a former researcher at Iowa State University, was sentenced to over 4.5 years in jail and ordered to return $\$ 7.2$ million dollars in funding that he had received for his research on developing an HIV (Human Immunodeficiency Virus) vaccine. His crime consisted in deliberately contaminating rabbit blood with human antibodies to make it look as if the animals were developing anti-HIV antibodies (Phillip, 2015). But he was not the first scientist to be jailed for malpractice, as several researchers had been sent to prison before him for similar transgressions (Ghorayshi \& Ferguson, 2015).

In late 2015, a list of the most alarming scandals that have occurred in science was published. It highlights cases of "dressing-up" or inventing data, of sexual harassment, and of sexual discrimination, etc. (Dvorsky, 2015). These incidents seem to suggest that cases of scientific malpractice are frequent and occur in diverse fields, so the question is: what can be done to eradicate such improper conduct? Many consider that a first key aspect is providing training in the area of ethical guidelines to everyone involved in scientific activities (researchers, professors, students, laboratory technicians). For, as Sieber (1992) points out in the Publication Manual of the American Psychological Association (APA), while ethical behavior in scientific research is clearly defined, this 
does not necessarily mean that individuals know what they should do, how they should go about doing it, and the ethical guidelines that apply to their specific area of scientific research.

Given these antecedents, the objective of this paper is to describe in detail the ethical principles that must be observed by those who conduct experiments in psychology (especially those involving human participants), and by those who write scientific reports. Our aim is to contribute to ensuring that scientific work is performed ethically.

The first task in this regard is to define clearly what we refer to when we speak of scientific malpractice. While no single definition exists, this rubric certainly includes the activities elucidated in the following pages.

\section{Scientific Fraud}

Scientific fraud can take several different forms: (a) "invention" occurs when an author fabricates some data in a study; (b) "falsification" and "manipulation" of data is when genuine, concrete data exist, but the author "adjusts" them to "fit" a hypothesis ("adjustments" may entail eliminating some data from a sample, or inflating or reducing certain values); and (c) "plagiarism", which is when an author presents someone else's ideas as her/his own without duly acknowledging the original source. To these modalities of scientific malpractice, Salinas (2004) adds some others; for example, stealing other people's research ideas, or stealing a complete project or observations made by another researcher. Since the third type-plagiarism—is probably the most common form of scientific malpractice, the following section focuses on this offense.

\subsection{Plagiarism}

Plagiarism is defined as using another author's ideas or words without appropriate acknowledgment (Owens \& White, 2013, p. 14). This problem arises especially among students in the formative stages of their career; i.e., potential scientists, as was evidenced in a study conducted with medical students by Huamaní, Dulanto-Pizzorni, and Rojas-Revoredo (2008), which found that of a total of 24 research papers reviewed, 23 had clear signs of passages copied from texts published on the Internet. Worse yet, $64 \%$ of the individual sentences evaluated in those papers were copied unchanged!

Because one- sometimes two-tutors had been assigned to supervise those students in the elaboration of their papers, the authors of this report questioned the responsibility of those advisers for the students' behavior, for it seems that they only lent their names without ever becoming actively involved in the conduction or reporting of the research. Such behavior is equivalent to feigning the status of honorary author, so it clearly constitutes a breach of ethics and labor law by those advisers (Huamaní, Dulanto-Pizzorni, \& Rojas-Revoredo, 2008).

A study of Masters' students enrolled in a "virtual" system offered by a public university in Mexico discovered that $71 \%$ of interviewees admitted to having plagiarized their papers ( $19.4 \%$ of them on multiple occasions!), even though they recognized that such conduct is "similar to theft" ( $71 \%$ of interviewees gave this description), and merits severe punishment (Larios, in preparation). Researchers in the United Kingdom, meanwhile, found that over $50 \%$ of the students they surveyed considered that plagiarizing information from the Internet was "acceptable" (Szabo \& Underwood, 2004). Intriguing results include the fact that plagiarism is more frequent among men than women (Underwood \& Szabo, 2003; Owens \& White, 2013), and more common among frequent Internet users and students at lower levels than higher levels of the educational system (Underwood \& Szabo, 2003). The latter result may be because more experienced students have learned and developed competencies for conducting research and writing scientific reports, and likely received more extensive training in the ethical aspects of scientific research during their formal academic careers.

But plagiarism occurs among both students and scientists with varying frequencies in different countries, as was demonstrated in a study by Bohannon (2014), a correspondent for the journal Science who analyzed hundreds of thousands of studies available on $\mathrm{arXiv}$, an Internet site that accepts articles (and not-yet-peer-reviewed drafts) in the fields of physics, astronomy, mathematics, informatics, non-linear science, quantitative biology, and statistics. Bohannon found that plagiarism was less frequent in articles by authors in industrialized countries (U.S., Canada, etc.). He attributed his results to cultural differences between industrialized and non-industrialized nations regarding academic infrastructure, systems of "teaching and supervision, and incentives that privilege quantity over the quality of publications" (Bohannon, 2014, final paragraph).

This widespread problem of plagiarism involving materials that circulate on the web has propitiated a proliferation of computer programs that compare the phrases of one text with Internet publications in order to calculate the degree of similarity between them. Examples of such programs are: Ephorus, SafeAssign, AntiPlagiarist 1.8, CrossCheck, Copyscape: Doc Cop, Dupli Checker, Plagium, The Plagiarism Checker and Viper. We suggest that before submitting texts for publication, authors should consider running them through one 
of these programs to verify that they do not (inadvertently) contain information from someone else's work without due acknowledgment.

\subsubsection{How to Avoid Plagiarism}

To avoid improper use of other authors' information it is necessary to: (a) give appropriate acknowledgment when one uses ideas, materials, images or data that are not in the "public domain" (see Appendix A, Part (a), for an example of proper accreditation in such cases); and (b) avoid "self-plagiarizing", which occurs when an author uses her/his own previously-published information without making this explicit. When one wishes to use information from another source it must be paraphrased. According to the Oxford English Dictionary, a paraphrase expresses the meaning of something written or spoken, using different words, especially to achieve greater clarity. In contrast, if a direct, textual quotation is to be included, it must be enclosed in quotation marks and followed by the page number(s) from where the information was taken (e.g., according to " $x$ " author (year) "such and such ..." (p.x)). It is important to clarify that all paraphrases must also be duly cited by identifying the original source of the idea, including the author's name and the year of publication (e.g., according to " $x$ " author (year) "such and such ..." (p. x)). The only difference between quoting and paraphrasing is that when the citation is textual it must be enclosed in quotation marks, since for paraphrases, the APA "recommends indicating a page or paragraph number, especially if this helps an interested reader locate the relevant fragment in a long, complex text" (APA, 2012, p. 171). Appendix A, Parts (b and c), shows examples of a textual quotation, an acceptable paraphrase and an unacceptable paraphrase.

Here it is important to emphasize that, while quoting other works is permitted, one must not "abuse this privilege", since texts that present mostly ideas taken from other sources are considered unscientific, even if proper acknowledgement is given (Miranda, 2013).

\section{The Lack of Ethical Conduct in the Process of Publishing Scientific Texts}

Common ethical errors in the process of publishing scientific texts include:

- "Fictitious" authorship (also called "honorary" or "ghost" authorship). This occurs when a person appears as a co-author of a document in which she/he did not participate. The APA (2010) states that a researcher may appear as an author of a paper only if she/he has genuinely performed the work involved, or made substantial contributions to it.

- "Exchanged" authorship means that the name of a co-author is added to one researcher's work in which she/he had no participation, in exchange for that person adding the researcher's name as co-author to one of her/his texts despite not being involved.

- "Repeated" or "duplicated" publication is when someone publishes all or part of a previously published study in another journal (or other print document or electronic publication) without the knowledge of the editors of the journals involved, and without indicating that the information has been published previously.

- "Fragmentary" publication; that is, segmenting one study to publish it "in parts" in order to increase one's number of publications.

- "Inflated" publication. This consists in publishing a previously edited article as a "new" work though only some data or additional cases were added, without the editor's knowledge, and with no recognition of this in the new text. This category does not include preliminary publications of long-term projects or the parallel publication of an article in different languages or for distinct audiences (e.g., in a textbook and in an article for divulgation).

- "Self-plagiarism", which refers to repeating information already published in previous works without due acknowledgment of this fact.

It is important to stress that scientific malpractice is not caused only by the absence of a code of ethics to which all research must adhere, as Richaud demonstrated (2007) in a study that revealed cases where researchers had full knowledge of all ethical regulations but simply failed to abide by them. That work set out to survey all 366 Undergraduate and Graduate Departments of Psychology in the U.S. to document how they work with research subjects and whether or not their procedures comply with federal law and APA standards.

A total of $89 \%$ of those departments agreed to answer the survey. They were randomly divided into two groups, one "anonymous", the other "confidentiality-identified". Results revealed widespread incompliance with ethical regulations, though the "confidentiality-identified" sub-group more often justified its violations of ethical norms than the "anonymous" sub-group. The study found that the respondents in the "identified" sub-group answered almost as honestly as those in the "anonymous" sub-group regarding the lack of adherence to ethical standards. 
Richaud's study concluded that scientific malpractice is not due to the absence of regulations and codes of ethics, since all the academic institutions involved were found to have these on their books. Rather, as the author points out (Richaud, 2007), at the end of the day, compliance depended on the level of honesty of individual researchers.

In an effort to preclude that adherence to ethical guidelines in scientific practice continue to depend on researchers' personal decisions, the $3^{\text {rd }}$ World Conference on Research Integrity was convoked in 2013. Participants in that event emitted the following recommendations: (a) improve the formation and supervision of researchers-in-training; (b) encourage journals to publish negative results; (c) reduce the pressure on researchers to publish; (d) ensure that all proposed studies are pre-registered before research begins; (e) formally teach ethical conduct; and (f) increase the severity of the sanctions imposed in cases of malpractice (Fanelli, 2013). Fanelli (2013) emphasized that "we often forget that scientific knowledge is reliable not because scientists are more intelligent, objective or honest than other people, but because their findings are subjected to review and replication" (p. 149).

One researcher who recently achieved notoriety is Uri Simonsohn, now known as "the data vigilante", because he designed a software program that uses statistical-informatic analyses of published data to detect scandalous frauds committed by scholars at prestigious universities in Europe and the U.S. (Torres, 2013). His discoveries have resulted in researchers being dismissed, or resigning, from their posts.

\subsection{How to Avoid Ethical Failures in the Process of Publishing Scientific Works}

To avoid committing ethical failures when writing reports of studies, strict adherence to the applicable ethical norms is mandatory. This means that researchers must never fabricate, invent or falsify results. It further obliges authors to publish a retraction or an errata when a published result is later found to contain an error.

According to Fanelli (2013) the U.S. Office of Science and Technology Policy defines falsification as the manipulation of research materials, equipment or processes, or the modification or omission of data or results such that the final report does not accurately record the work done and the data obtained.

When conducting research, one must avoid committing scientific fraud because, as Salinas (2004) states, "[this] is one of the most severe faults that a scientist can commit, whether [she/he] is a researcher, professor, academic, businessman, industrialist or [someone who] acts in any situation in which her/his principle activity is science" (p. 42). This clarifies the important fact that scientific fraud cannot be committed by just anybody; rather, it is a con-job perpetrated by individuals who have scientific expertise and require sufficient and necessary knowledge of their discipline to dupe evaluators (Salinas, 2004).

To avoid committing scientific fraud in any of its modalities, scientists are obliged, among other things, to accept credit only for the work they have performed, to ensure that the order of authorship of an article reflects the level of contribution of each co-author in the study and duly acknowledge the work of individual members of a research team, and not to publish the data more than once (unless this is, for some reason, unavoidable, in which case it must be duly indicated).

Also, it is important to eliminate any outside influence; for example, pressure from others to be cited or to be mentioned in a study in which they had no significant participation, or to have their work published. It is completely unethical to offer gifts or perform favors for others in order to obtain benefits of this kind.

\section{Ethics in Research with Human Participants}

\subsection{Research Planning}

It is essential to observe ethical behavior right from the moment one begins planning a research project, taking into account the following considerations.

- Before conducting research one must ensure that all participants have the required scientific competence, and that they are aware of, and know how to comply with, the applicable ethical standards in accordance with the characteristics of the research to be carried out. This will guarantee respectful and dignified treatment of all participants, minimize the risk of obtaining erroneous results, and ensure the validity of the work performed.

- The research protocol must be submitted to an Ethics Committee at the institution in question before beginning the study to ensure that it complies with the ethical standards that are pertinent to the specific kind of research proposed. 
- When working with animals or human subjects, it is essential to guarantee: (a) that the research has social value; i.e., that it constitutes a beneficial contribution to mankind; and (b) that it has scientific validity in the sense that it adheres to established protocols for the type of research (Aristizábal, 2012).

- If the proposed study involves human participants it is essential to obtain the informed consent of each one (a point analyzed in greater detail below), and to take all necessary measures to guarantee their physical and psychological wellbeing and respect for their rights. All participants must be treated with courtesy, respect and dignity at all times. Also, the confidentiality of all sources of information (students, patients, clients, organizations, etc.) must be duly protected.

- When working with animals, researchers are obliged to adhere strictly to the ethical regulations established in the Official Mexican NORM, NOM-062-ZOO-1999 (http://www.fmvz.unam.mx/fmvz/principal/archivos/062ZOO.PDF), which stipulates the technical specifications for the production, care and use of laboratory animals.

- If the research utilizes instruments or materials that are copyright-protected, the researcher is legally-bound to obtain the corresponding authorization in writing.

- In the event that the research will utilize research instruments, procedures, or unpublished data that other researchers may consider their personal property (exclusivity), it is essential to request -in writing-authorization for their use, as well as the corresponding permission, also in writing. The objective of this procedure is to avoid possible conflicts at a later date. Finally, in both cases 6 and 7, the researcher must give appropriate credit in the final document.

- The authors of all published works cited must be duly acknowledged in the final manuscript. Also, care must be taken to ensure that all works so cited similarly adhered to the ethical standards applicable to the case (Aristizábal, 2012).

- Another fundamental point is that authors must describe truthfully and accurately the procedures or protocols followed in performing the research in their reports. It is a violation of ethics to deliberately falsify or omit information that would impede other researchers from replicating the research performed in conditions similar to those of the original study.

- In order for participants to appear as co-authors of the final report, each one must give her/his express authorization to be included. It is also necessary to ensure that all authors agree with the order proposed for recognizing their authorship.

\subsubsection{Informed Consent}

Given the vital importance of this instrument in the conduction of experiments with human subjects, we examine it in great detail. First, it is important to understand that providing potential participants with full and detailed information regarding the implications of their participation in a particular study is a legal obligation (for example, U.S. regulations are stipulated by the Committee for the Protection of Human Participants in Research). Strict adherence to the applicable ethical guidelines demands that all potential participants can decide freely and voluntarily whether they wish to participate in a given study; thus, researchers must guarantee that they receive all the relevant information required to make an informed decision. An "informed consent letter" must explain all necessary information in simple, clear and precise terms to ensure that potential participants fully understand it. No person can be pressured, coerced or tricked into agreeing to participate (Richaud, 2007).

An informed consent letter must mention the total number of sessions programmed for the study and the duration of each one, and researchers must ensure that the duration of the sessions is adequate for the study population: for children, 5-15 minutes; for adolescents or adults, maximum 2 hours (Pilgrim, 1998). The aim is to avoid undue fatigue.

In addition, the letter must mention the possible benefits (if any) that may be obtained by participating, as well as any type of inconvenience or adverse stimulation that may be involved. In the latter case, participants must be duly informed of all such conditions, and it is the sole responsibility of the researcher to ensure that participants fully comprehend the implications of such conditions. The letter must also state clearly and explicitly that the participant is free to abandon the study at any time if she/he so decides; and that such abandonment shall not entail any type of negative consequence whatsoever.

Since making sure that all human participants attend all the sessions programmed for a study can be difficult, it is permissible to employ certain strategies to control this problem, though care must be taken to ensure that no such strategy is in any way coercive. Under no circumstances can a participant be pressured or forced by threats, 
whether explicit or implicit. In contrast, it is acceptable, for example, to offer an incentive for each session attended and/or a bonus for completing all sessions. Another acceptable option is "raffling off" one sole incentive among all participants at the end of the study (Pilgrim, 1998).

Care must be taken, as well, to ensure that the incentives offered are suitable for the study population in question (e.g., money for adults, academic credits for university students, etc.), and not overly costly. This is important because, for example, in the case of low-income participants, hefty incentives could function as a coercive strategy that tempts them to agree to participate out of economic need without duly evaluating the implications of said participation. Also, no incentive may include anything that is harmful to human health (e.g., cigarettes, junk food, etc.). Finally, if the research involves children, it is obligatory to obtain the authorization of the parents before giving any incentive (for this population appropriate incentives may be fruit, school supplies or small toys).

The informed consent letter must also specify the kind of incentive that will be offered, and under what conditions. It is important to understand that this letter is a contract celebrated by the experimenter and participant, so it is only valid if signed by both parties and if each one conserves a copy (APA, 2010). If the study involves children or persons who for any reason are unable to decide for themselves, then a parent, tutor or guardian shall sign in their stead. Appendix B presents a template of an "informed consent letter" that can be adapted to the specific conditions of each case.

If one intends to work with participants who are under the care of an institution (e.g., students, club members, patients at a psychiatric institution, etc.) it is necessary to obtain the informed consent of the appropriate legal representative(s) as well. An informed consent letter for institutions must contain at least the following information (as per Pilgrim, 1998):

- description of the target study population;

- number of participants required;

- a brief explanation in simple language of the nature and aims of the study;

- a description of how the research will be conducted;

- a description of any apparatuses or procedures that will be employed;

- possible benefit(s) (individual and institutional) of participating in the study;

- a description of the kinds of data to be gathered;

- any potential risks for participants; and

- a copy of the informed consent letter.

There are, of course, occasions when the nature of the study requires limiting the amount of information provided, or even giving false information. In such cases, provided that all procedures have been duly reviewed, justified and authorized by a formally-constituted Ethics Committee, it is permissible to conduct the work. However, the experimenter must ensure that participants are aware that some aspects of the research may not be revealed until the study concludes. Here, it is essential that the researcher makes sure that the risks are minimal, and that there is an adequate plan to: (a) provide participants with the complete or true information at the appropriate time; and (b) inform them of their results, if they so desire (Richaud, 2007). In fact, informing participants of their results is not mandatory only in these cases, but under all circumstances; that is, once the subject's participation, or the study itself, ends, all subjects must be fully informed of the nature, objectives, results and conclusions of the research, as well as of their own data, if they so wish (APA, 2010).

Regarding the risks that may be involved in participating in a project, it is important to recognize that it is not always possible to identify them, much less accurately quantify them, at the outset. For this reason, it is essential to obtain the approval of an Ethics Committee that will support the researcher in the decision-making as to how to best conduct the study and help her/him perceive when the risks begin to outweigh the potential benefits (Sieber, 1992). In such conditions, research must be suspended immediately.

\subsubsection{Confidentiality}

Another particularly important aspect of research with humans is ensuring that all information collected will be treated with complete confidentiality. In this regard, the first step consists in obtaining each subject's permission to record data, specifying the means that will be used for this purpose (i.e., video, tape-recording, computer registration, etc.). Second, codes or keys must be used when storing subjects' personal data to preclude identification. Third, care must be taken to minimize the intrusion into the private life of participants by limiting 
requests to only the information that is essential for the objectives of the study. Fourth, the personal information gathered can only be revealed (without the participant's consent) under judicial order when said data is relevant to an ongoing investigation. Of course, this information can be used for didactic purposes and can be included in presentations at academic events or in publications, provided that participants' privacy is respected (APA, 2010). Finally, all such records must be held for at least 5 years after the date of publication of the report in question in case the need for clarifications arises in the future.

\section{Ethics in Research in Cyberspace}

A scandal occurred in June, 2014, when it became public knowledge that a study had been conducted with almost 700,000 Facebook users in which the number of positive and negative messages they received in their actualizations was deliberately manipulated during a one-week period (in January, 2012) to determine whether those changes affected the emotional tone of the individuals' ensuing messages. The objective of that study was to explore how emotions are propagated in large populations (Goel, 2014). The problem was that none of the users involved knew that they were (unwittingly) participating in a psychological experiment. This is an extremely serious situation because while "face-to-face" research requires obtaining the informed consent of each and every participant, it seems that researchers who conduct studies through virtual media no longer consider such requirements necessary, despite the fact that the potential risks for participants are similar.

As a result of the polemic triggered by that study, many universities and research centers have organized panels to debate the nature of the ethical guidelines that must be followed for online research. To date, the consensus is that feedback systems must be developed and implemented so that researchers can obtain informed consent, but this only means applying the same measures that are compulsory for face-to-face research.

Regulating the use of the information of Internet users is a fundamental task in developing guidelines for research (e.g., psychological studies carried out on social networks) that has the clear potential to provide extremely valuable data that could lead to a better understanding of the behavior of human populations. For example, the virtual communities of support groups can be invaluable sources of data for researchers (Spriggs, 2009).

Broadly-speaking, studies conducted over the Internet have adopted one of the following strategies: (a) passive analysis; i.e., observation-only, where the researcher is not part of the group. While this is considered "non-intrusive", participants are unaware that they are being observed; (b) active analysis; i.e., the researcher does form part of the virtual group. This is classified as "intrusive" only when participants are not informed that they are being analyzed; (c) research similar to the face-to-face approach, where the researcher identifies her/himself as such and asks potential subjects to participate (Spriggs, 2009, p. 322).

The debate as to whether or not it is ethically correct to conduct passive analyses without informing participants that they are objects of analysis rages on.

\section{How Can We Eradicate Scientific Malpractice?}

As mentioned at the outset, a three-pronged strategy has been proposed to eradicate scientific malpractice. The first essential element obliges academic institutions (universities, research centers, etc.) to provide continuous training in the ethical aspects of the discipline in question for everyone involved in scientific work: researchers, technicians, professors, students, etc. Second, institutions must ensure constant, close supervision to guarantee that all scientific activities are conducted under strict observance of the applicable ethical standards. The third and final fundamental aspect requires defining mechanisms that stipulate sanctions and how they are to be applied in the event of scientific malpractice.

It certainly seems that incidents of scientific malpractice are becoming more frequent, though it may be that they are occurring with the same frequency as before but now, thanks to the electronic media, are easier to detect. What is clear, however, is that the ever-greater availability of all kinds of materials online appears to be contributing to an increased incidence of plagiarism, to mention only one example. Nonetheless, the principle factor that seems to lie behind the proliferation of instances of scientific malpractice may well be the fact that those who commit it rarely suffer serious consequences, since even clearly-identified cases of malpractice are often simply ignored.

In the concrete case of plagiarism, as several studies of this phenomenon have demonstrated, the vast majority of people who plagiarize are perfectly well aware that this act is incorrect (even comparing it to robbery), but this does not deter them from committing this serious form of malpractice. Given this, we consider that it is essential to develop a legal framework that will more rigorously regulate scientific practice than the one currently in effect. This may be especially urgent in developing countries.

In Mexico, no protocols describe procedures that could be implemented to (a) identify; (b) investigate; and (c) if justified, sanction, scientific malpractice. For this reason, it is urgent to set to work on designing strategies that will 
not only propitiate the identification of scientific malpractice, but also establish and enforce sanctions that are judged adequate for each type of transgression, while simultaneously forming agencies entrusted with the task of determining and applying those sanctions. All of the aforementioned activities and strategies are essential if we are to be serious about eradicating this type of conduct, for they constitute the only way to guarantee that the results of scientific work achieve greater reliability.

\section{References}

American Psychological Association. (2010). Publication Manual of the American Psychological Association. Washington, DC: American Psychological Association.

Aristizábal, L. E. (2012). El por qué de la ética en la investigación científica. Investigaciones Andina, 14(24), 369-371.

Retrieved

from http://www.scielo.org.co/scielo.php?script=sci_arttext\&pid=S0124-81462012000100001\&lng=en\&tlng=es

Bohannon, J. (2014, December 11). Study of massive preprint archive hints at the geography of plagiarism. Science. Retrieved from http://news.sciencemag.org/scientific-community /2014/12/study-massive-preprint-archive-hints-geography-plagiarism

Bravo, R. (1997). Aspectos éticos en las publicaciones científicas. JANO, 52(1208), 74-76.

De Martos, C. (2011, November 3). El holandés farsante. El Mundo. Retrieved from http://www.elmundo.es/elmundosalud/2011/11/02/biociencia/1320265403.html

Dvorsky, J. (2015, December 18). The Most Notorious Science Scandals of 2015. Gizmodo. Retrieved from http://gizmodo.com/the-most-notorious-science-scandals-of-2015-1748385638

Fanelli, D. (2013). Redefine misconduct as distorted reporting. Nature, 494, 149. http://dx.doi.org/10.1038/494149a

Goel, V. (2014, August 31). El dilema ético de analizar a los usuarios en Internet y las redes sociales. La Nación. Retrieved from http://www.lanacion.com.ar/1722810-el-dilema-etico-de-analizar-a-losusuarios-en-internet-y-las-redes-sociales

Ghorayshi, A., \& Ferguson, C. (2015, July 2). Science Frauds Who Steal Tons of Federal Money Almost Never Go To Jail. Buzz $\quad$ Feed $\quad$ News. $\quad$ Retrieved from http://www.buzzfeed.com/azeenghorayshi/most-science-frauds-never-go-to-jail\#.arloqDVoW

Huamaní, C., Dulanto-Pizzorni, A., \& Rojas-Revoredo, V. (2008, June). Copiar y pegar en investigaciones en el pregrado: Haciendo mal uso del Internet. Anales de la Facultad de Medicina, 69(2), 117-119. Retrieved from $\mathrm{http} / / /$ revistasinvestigacion.unmsm.edu.pe/index.php/anales/article/view/1154

Larios, S. (in preparation). Plagio de información en la modalidad de educación virtual.

Martínez, G. (2015, July 6). Nuevo caso de plagio serial en la academia. El Universal. Retrieved from $\mathrm{http} / /$ beta.eluniversal.com.mx/articulo/cultura/letras/2015/07/6/nuevo-caso-de-plagio-serial-en-la-academia

Miranda, A. (2013). Plagio y ética en la investigación científica. Revista Chilena de Derecho, 40(2), 711-726. http://dx.doi.org/10.4067/S0718-34372013000200016

Owens, C., \& White, A. F. (2013). A 5-year systematic strategy to reduce plagiarism among first-year psychology university students. Australian Journal of Psychology, 65, 14-21. http://dx.doi.org/10.1111/ajpy.12005

Phillip, A. (2015, July 1). Researcher who spiked rabbit blood to fake HIV vaccine results slapped with rare prison sentence. The Washington Post. Retrieved from https://www.washingtonpost.com/news/to-your-health/wp/2015/07/01/researcher-who-spiked-rabbit-bloodto-fake-hiv-vaccine-results-slapped-with-rare-prison-sentence/

Pilgrim, C. (1998). The Human Subject. In K. A. Lattal, \& M. Perone (Eds.), Handbook of Research Methods in Human Operant Behavior (pp. 15-44). New York: Plenum Press. http://dx.doi.org/10.1007/978-1-4899-1947-2_2

Richaud, M. C. (2007). La ética en la investigación psicológica. Enfoques XIX, 1-2, 5-18.

Salinas, P. J. (2004). Fraude científico en el ambiente universitario. MedUla, 13, 42-47.

Sieber, J. (1992). Planning ethically responsible research: A guide for students and internal review boards. In Applied Social Research Methods Series. Newbury Park, CA: SAGE Publications. 
Spriggs, M. (2009). Consent in Cyberspace. Monash Bioethics Review, 28(4), 25-39. http://dx.doi.org/10.1007/BF03351319

Szabo, A., \& Underwood, J. (2004). Plagiarism: Is this a problem in tertiary education. School of Science, Nottingham, UK: The Nottingham Trent University.

Torres, F. (2013, March 30). Uri Simonsohn, el detective de datos. La Tercera. Retrieved from http://papeldigital.info/tendencias/2013/03/30/01/paginas/022.pdf

Underwood, J., \& Szabo, A. (2003). Academic offences and e-learning: Individual propensities in cheating. British Journal of Educational Technology, 34, 467-477. http://dx.doi.org/10.1111/1467-8535.00343

\section{Appendix A}

Examples of: (Part a) how to give adequate acknowledgment when using Tables or Figures from other works; (Part b) a correctly-referenced textual quotation; and (Part c) an acceptable and unacceptable paraphrase.

Part (a)

Example of how to properly acknowledge a Table or Figure from another source.

In the case of Tables, Figures, Images, Photographs, etc., immediately after the description of the element, the author must add a legend or caption that begins with "Taken from..." and then notes the original author's name, the year of publication, the title of the publication, the means of publication (i.e., the name of the journal or the title of the book or article) and the corresponding page number. These data must be separated by commas.

Part (b)

Example of a textual quotation (correctly-referenced).

Textual quotation:

"We expected around a $75 \%$ response rate (that in reality turned out to be $89 \%$ ) which represented a sufficient number of subjects to perform a random assignation of the departments to two conditions: anonymous and confidentially-identified" (Richaud, 2007, p. 7).

Part (c)

Examples of an acceptable and an unacceptable paraphrase.

Acceptable paraphrase:

$89 \%$ of departments that agreed to answer the survey were randomly divided into two groups: anonymous and confidentially-identified (Richaud, 2007, p. 7).

Unacceptable paraphrase:

It was believed that only $75 \%$ would respond, but because $89 \%$ responded it was considered that this was a sufficient number to perform a random assignation of the departments to two conditions: anonymous and confidentially-identified.

\section{Appendix B}

Example of a letter of "Informed Consent".

\section{FORMAT FOR INFORMED CONSENT}

\section{UNIVERSITY OF GUADALAJARA}

We thank you for your valuable participation and ask you to be aware of the following:

- The present study is composed of 3 half-hour sessions (one per day).

- During each session you will be asked to perform a program on a computer.

- None of the activities contemplated in the study entail any type of risk or physical or psychological discomfort in the short or long term.

- This study was designed to investigate how people learn certain things. The aim is not to evaluate personality, intelligence or memory. The task you will be asked to perform involves interacting with a 
group of figures by clicking on them according to indications shown on a computer screen. The computer itself will record the data you generate.

- If you do not wish to finish the task, you can conclude your participation in the study at any time by informing the researcher in charge. This will not entail any type of negative consequences for you.

- We clarify that the data you provide on this format, as well as the information recorded on the computer, will remain strictly confidential and will be utilized exclusively for research purposes.

The following are the conditions under which the researcher can terminate your participation in the study:

$\circ$ Any behavior that endangers property or other persons involved in the study, or

o Failure to perform any of the tasks solicited.

UNDER NO CIRCUMSTANCES CAN YOU DIVULGE INFORMATION REGARDING THE TASKS AND PROCEDURES CARRIED OUT IN THIS STUDY BECAUSE THAT COULD AFFECT OTHER STUDENTS.

I declare that I am participating voluntarily in the research, that I have read and understood the information presented in this format of consent, and that I agree with the conditions established in it.

Signed in conformity on the day of the month of of the year

\section{Copyrights}

Copyright for this article is retained by the author(s), with first publication rights granted to the journal.

This is an open-access article distributed under the terms and conditions of the Creative Commons Attribution license (http://creativecommons.org/licenses/by/3.0/). 